JOURNAL OF ENGLISH STUDIES, I (1999), 69-80

\title{
IMAGINATION AND NONLITERALITY: A CASE STUDY OF SUPERHUMAN ENTITIES IN RELIGION
}

\author{
Mª Dolores FernándeZ de la Torre MAdueÑo \\ University of Málaga
}

\begin{abstract}
In the present work we would like to emphasize the aspect of imagination as an element of great relevance in the production of metaphorical processes. With the experientialism upheld by the cognitive approach, people's imaginative ability is established as one of the main arguments to face any lexical analysis from a cognitive perspective.

A double focus can be appreciated in the religious vocabulary: On one hand, the experience that the members of a linguistic community live directly and personally and on the other hand, a virtual creation of such an experience, a sort of "imagined experience". In it, imagination would be characterized by the ability to transfer certain conceptualizations and ideas to human domains; conceptualizations and ideas which, from a theological point of view, are neither present nor located in such domains. This focus centers on a series of religious lexemes of a superhuman nature, angel and devil.
\end{abstract}

The imaginative work constitutes a constant activity in human beings' lives, or in the "imaginative beings", as Johnson notes (1992: 349). Such a task takes place when individuals perceive, conceptualize, or reason, and imagination is a sort of unavoidable complement to these mental activities.

By means of metaphorical projections, it is possible for certain domains -which do not apparently show any kind of reciprocal association- to get a coherence that makes feasible the comprehension of a message. The associations that occur between the source domain and the target domain have effects on the lexicon directly, since the conceptualization of a domain in terms of another domain, which is independent of that one, involves the lexemes implied in the process. In the present work we will analyze the 
relevance of imagination in the production of metaphorical processes, especially in connection with religious superhuman lexemes in English.

As a result of the metaphorical projections that may take place in a word, new meanings arise for a same word. These meanings are somehow structured since users can identify or, at least, guess the links existing between the domains implied. In fact, "the lexical organization of words (...) is structured by general cognitive principles that are systematic and recurrent throughout the lexicon (...) These principles arise from our phenomenological embodied experiences (...) bodily experience partly motivates people's intuitions as to why different senses [of a word] have the meanings they do." (Gibbs and Colston 1995: 352). From this point on, we should state that there exist links, either between the different meanings of a word (and then, the implied domains) or the very experience of language users. So nonliterality is the result of cognitive and linguistic relationships, but also with a quite important degree of empirical behaviour. Imagination is highly connected with people's lives, cognitive processes, and language itself.

\section{The ROLE OF IMAGINATION AS A COGNITIVE PROCESS}

In the production of nonliteral meanings of a metaphorical character, the projections may be seen as movements of certain aspects of experience and knowledge from one domain to another. Consequently, when several specific domains of experience are used to structure other more abstract domains, metaphorical projections operate. They work as basic agents to move preconceptual structures of our experience from one domain towards another domain which lacks some kind of preconceptual structure. As a result of this, both speakers and listeners can understand these last domains of experience which would lack, in principle, a preconceptual structure (Lakoff 1987: 303). The projections between two domains are based on the similarities, and on the experiential correlations as well, existing between the domains (Lakoff and Johnson 1980; Johnson 1987; Lakoff 1987; Lakoff and Turner 1989). Prototypical ideas generalize and determine the associations and projections between domains (cf. Geeraerts 1992). This may be considered one of the reasons by which nonliteral meanings exist and are possible.

\subsection{Johnson's cognitive account of imagination}

Johnson (1987) shares Kant's account of imagination as “a capacity for organizing mental representations into meaningful unities that we can comprehend. Imagination generates much of the connecting structure by which we have coherent, significant 
experience, cognition, and language [sic]" (p. 165). As an entity with neither metaphysical nor epistemological separations for Johnson, he defends imagination as "a pervasive structuring activity" which makes possible our achievement of coherence and unification of representations suitably patterned. Human rationality seems to be rather distant, if it is not the exact oppposite of imagination. However, it is precisely imagination which makes feasible the rational work, since imagination makes possible the rational associations and inferences, or more or less intelligent solutions and answers to questions about our lives (cf. Johnson 1987: 168).

Going on with this cognitive proposal, Johnson (1992) focuses imagination as the capacity of stimulating and developing different degrees and levels of relevant order in our experience. Imagination allows us to grasp the form and compose new orders of experience. On their part, Turner and Fauconnier (1995: 183-202) establish that the metaphor shows a partial projection from two incoming structures to create a third structure. We would like to remark that, in the projection and in the creation of the latter structure, imagination plays an essential role. Thus, imagination will center on discovering productive ways of integrating greater registers of conceptual structures in a relevant scenery. The listener, when picking up and understanding the message, must have access to such registers.

Johnson (1987: 169) remarks the importance of imagination as a creative process. Experience is reshaped by the connections and projections of structure that take place in our minds. Metaphoric and metonymic patterns, by which such schemata become dynamic, reinforce the role of image-schematic structures. Johnson (1992: 350) offers another definition of imagination as "our capacity for working up various degrees and levels of meaningful order within our experience". In explaining it, Johnson remarks how image-schemata act on our experience and on the assimilation of the world by individuals: image-schemata may subtly change a specific situation and/or people's configuration of their environment, their knowledge, and their world.

A social perspective of imagination may lead us to the following starting point: the linguistic community is so called because it shares a same language. Thus, we could talk about the "imaginative community", since the members of a same community (or a certain social group) share:

a) the ability for imagination to create (Johnson 1987: 169);

b) the ability for imagination to transform (Johnson 1992: 350);

c) the different types of imaginative structure (Johnson 1987: 168);

d) the way imagination let interchange aspects of the individual and collective selfhood (cf. Johnson 1992: 357); 
e) the structures of imagination when understanding one another and communicating within the community (cf. Johnson 1987: 171-2)

Johnson (1992: 358) remarks the importance for a theory of imagination of the social aspects of creativity in relation with prototypes and the semantics of our understanding. Imaginative structures are basic in the transformations of these semantic tools, as well as in being shared in a social context. "Imaginative dimensions" are characteristic of both human conceptual system and reasoning.

The importance of this social side of imagination is particularly analyzed and reinforced in Johnson (1993a). Critical attitudes or perspectives would not be possible if this social imagination was not a fact. A range of variants, which may change in regard to the core, characterizes the prototype structure of our moral concepts, apart from one's own stable core. This variety does not go unnoticed in users: different framings, different construals (Johnson 1993a: 12; cf. Cienki 1998). We may add that such a variety is highly connected with how imagination works in a social context; moral issues are just only one of the possibilities in the range. In a way, we can carry out a contrast between the variety of alternatives which may take place in social imagination with Way's approach of the metaphor as "a set of "masks" which change the view of the semantic hierarchy" (1991: 126). According to Way, the combination of different masks gives place to new creations; thus, the specific "mask" coming into play will determine the absence or the varying degree of metaphoricity in an utterance, since such a mask shows the presence and connections in the hierarchy.

\subsection{Imagination, experience, and meaning}

In the experience of a linguistic community the analysis of the production form and subsequent evaluation of meanings may be remarked. In such acts, the environment, both the individual's and the community's, become partially or totally implied in their cognitive processes. "All of our structured modes of acting, thinking, and feeling (from simple habits to complex imaginative structures) incorporate part of our objective environment physical, cultural, and interpersonal within themselves (...)" (Fesmire 1994: 152). However, environment is only an element of the entire puzzle.

Leddy (1995) refers to the notion of "essences" as "culturally emergent entities [which] are embodied in physical objects and their relations (...) [they] are constituted in cultural space and are recognized by suitably culturally prepared observers" (p. 208). Leddy remarks the importance of experience, since it forms an intrinsic part of the world. Thus "essences are patterns in the "world-as-experienced" (p. 210), since they depend on human interactions (they are patterns, and the matter of a shared experience) 
and are intersubjective (they are constituted in a process that is dialogical between two or more persons).

From our point of view, meanings should be considered not only as parts of constitutive and cognitive processes in human experiences, but as mere experiences in themselves. That is to say,

a) with regard to human experience, considered as a whole, meaning performs a function of influence on human knowledge, habits, traditions, etc., in such a way that it becomes a constitutive element in our lives, and

b) a consideration of meaning as an organic process leads to making up of meanings as experiences by themselves.

Certain circumstances and specific events gather for a meaning to appear, be modified, or become obsolete. A consideration of meaning -as well as the whole process around- as the sender or the recipient of influences will make possible this double perspective of the idea of meaning. The double-sided experience of meaning makes us pose a similar duality. On one hand, a collective outlook when meaning is a part of the experiences of the group or of the individual in the community. On the other hand, an individual side, in the configuration of a certain meaning in isolation and as the result of a series of circumstances.
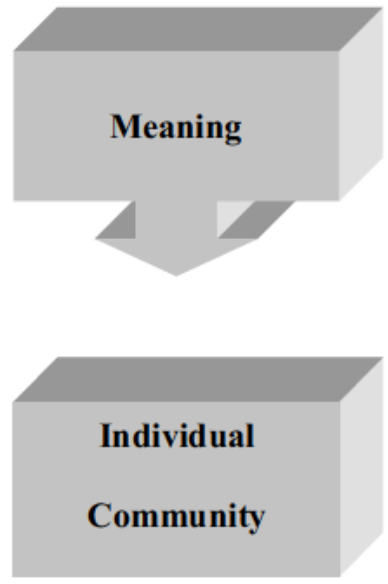

Collective side
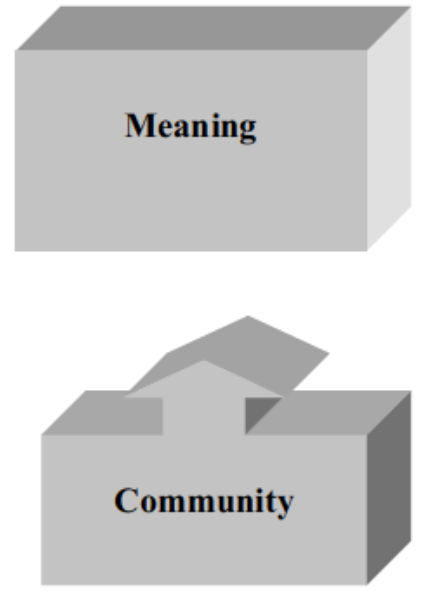

Individual side

\section{Double-sided experience of meaning}


As far as we are concerned, imagination should receive an alternative approach in relation to the lexicon. The production of nonliteral meanings is bound to the imaginative processes of the mind, apart from other cognitive processes. Since a nonliteral utterance is understood, and consequently, rejected or accepted, an element of rationality, originated in the mind, can be appreciated. Because of human constraining by mental operations, beliefs, and commitments (cf. Gorayska 1993: 48), we can establish that speakers tend to overgeneralize the same cognitive processes in the rest of the members of the linguistic community. Owing to this, when users make up or employ nonliteral meanings, a rather similar mental functioning is expected from the others. Thus, categorization principles, prototype formation, metaphorical mappings and so on take place in human minds. Nevertheless, there are certain crucial factors (background knowledge, cultural, social or moral perspectives and attitudes, and imagination) that play a defining role in how individuals carry on all these cognitive processes. Among its many functions, imagination gathers all these previous sources of human, mental and behavioural wealth, so that different results or targets are posssible by means of how our minds cognitively work.

Being conscious of all these considerations we may seek to expound that imagination is not strictly considered as irrational, subjective, and abstract, as it lies on mentally logical and concrete elements. Such elements can seem logical, if they are observed in an independent way. Nevertheless, the nonliteral meaning which may take place in an utterance may constitute a double evidence. On one hand, an apparently logical relationship takes place between two entities, from the point of view of the concrete reality. On the other hand, such a relationship has been, finally, admitted as one of the parameters of logicity which have been determined, at least partially, by imagination.

So imagination plays a relevant role in the organization of "that" reality in which the members of the linguistic community are placed. Rationality does not constitute a parallel alternative to imagination, but a factor that is closely linked to imagination. That is because both act for a relation of order to be produced, for a restructuring of experience to be based on new classifications and associations.

Imagination, as a creative agent for abstract worlds, adds a nuance of novelty on what has been previously established, but without disconnecting it from the logicity the linguistic community rests upon. Imagination seems to unbind a series of ideas with regards to what is purely rational, although we could admit a certain independence from that rational basis, the starting point of every imaginative activity.

\section{IMAGINATION AND RELIGION}

For Johnson (1993b: 71) and Sinha (1993) there is a recognition of both stability and imaginative diversity existing at the levels of our bodily, social, linguistic, and cultural 
environments (cf. Sinha 1993: 57). The environments mentioned by both Johnson and Sinha may result familiar, in a varying degree, for the members of the community.

All these environments can be cognitively analyzed from the religious point of view. Firstly, as an inner feeling, religion becomes a bodily experience for the members of the religious group. In this case, we paradoxically refer to a "non-material sensation", an invisible part of the spiritual relationship between the divine and the human being. However, another side of this bodily experience could even be considered as a physical perception. This is the case of mystics and of people who suffer from mysterious and, apparently, miraculous stigmata on their bodies. These people begin to perceive a series of pains, of unnatural experiences -such as levitation-, of visions, of smells, of sounds. In fact, we relate a series of experiences in which both physical and spiritual perceptions are openly connected to the religious experience. Similarly, the practical and ritualistic side of religion implies, in most cases, perceptive acts -such as having Communion, attending Mass, the confession of sins, internal and external prayers, listening to the Sacred Scriptures and comments on them, etc.

Secondly, a social side of religion implies its consideration as a group experience. A specific religion characterizes a community in a very significative way. As imagination is focused in its social perspective, a similar treatment may be given to religion, since many acts, either individual or collective, are contemplated from a religious point of view. This point will vary according to its degree of presence in the community. The external, social side of religion includes experiences of the sort of rituals, protocols, or public acceptance or rejection of specific dogmas, beliefs, or mysteries. It is quite curious to contrast the image the community has of the "professionals of religion" (priests, nuns, bishops, etc.) and how they have become conceptualized in language (Fernández de la Torre Madueño 1997).

Thirdly, our linguistic perspective of Christian religion could be briefly explained in terms of:

a) the linguistics of the Sacred Scriptures (God's Word), their interpretations, and the Christian doctrine;

b) the linguistics of the rituals, including the whole tradition in Latin language;

c) the linguistics of the Church and its principles of government and guidance;

d) the nonliteral side of religion, or how religious concepts and mysteries are explained by means of metaphorical language, parables, or proverbs;

e) the presence of linguistic religion outside the religious environment, that is, in the daily world. Religion has its particular lexicon, structures, mappings, and projections to and from domains that are not particularly religious, according to a specific experience that has determined it in such a way. 
Finally, the cultural aspects of a community include those connected with religion as well. Sacred music, the artistic representation of the Christian traditions and faith, the world of Christian fiction in literature, and the conservation of literacy and culture in monasteries are crucial in the Christian tradition, and constitute highly worthy experiences for the configuration of the linguistic religious community.

This multi-faceted experience is possible by means of imagination. The very assimilation of it can be carried on, as we have already seen, in separate, apparently independent, environments, or as one, unique set containing a multiplicity of aspects (linguistic, social, etc.). This latter case would be the suggestion we referred to at the beginning of this section, that is, the item we suggested to be added to those pointed out by Johnson and Sinha. The four environments they talk about, we think, are interconnected, and each one of them is characterized by aspects of the other three. So then, we have showed, in general terms, how religion is interrelated with the bodily, social, linguistic, and cultural environments. Similar links can be found between each one of the four environments, and cultural, social, linguistic, and bodily aspects will be characterized by one another. Consequently, religious aspects will be present in such considerations, and the other four will determine religion, as well.

\subsection{Beyond this world: superhuman entities become humanized}

The conceptualization of a superhuman entity in terms of specific human entities is essential in the determination of metaphorical processes that, later, are going to evolve into nonliteral meanings. Imagination becomes an unavoidable element in such conceptualizations, since there exist elements of a nature beyond the earthly and human ones. In such a situation, imagination may give place to creativity and inventiveness when trying to become nearer and nearer that unknown world, in a desire to grasp, to understand, and to make it its own. In one word, to assimilate it. Consequently, the linguistic Christian community has got a series of traditional stereotypes and images of those entities that are located in the Beyond.

Regarding the superhuman beings, we are going to focus on angels and devils. They constitute fundamental prototypes in the heavenly hierarchy that, according to the theological doctrine, does exist in heaven and hell, respectively. A few cases will be analysed next as examples of the influence of religion in the linguistic environment, particularly outside the religious world and in the non-religious lexicon.

The community has a rather special experience regarding these superhuman beings of Christianity. As a result of mixing and interweaving traditions, dogmas, and popular beliefs, both angels and devils are characterized according, mainly, to the community's 
imagination. Thus, angels and devils, as prototypes, may be the obvious product of the imaginative community, and every kind of projection or mapping will be necessarily linked to the way the community has adapted itself to these beings. Since they are unreachable and do not directly belong to the world, they have been given a humanized dimension, and then become associated, categorized, and assimilated as if they had that so-called humanized dimension. As an evident consequence of these cognitive processes, language offers many examples in which we can find that these superhuman beings might be one of us in some cases, although they do not obviously belong neither to the community nor to our "real" world as we conceive it. However, both from cognitive and linguistic levels, the members of the linguistic community handle these entities as freely and naturally as if angels and devils inhabited the very same community.

a) These superhuman beings are, by their very unknown nature, linked to mystery. Thus, in the case of angel, the feature "mystery" is evident when the term refers to a strange signal in the screen of a radar.

b) These beings have been characterized by certain functions. Angels are sent by God to keep humans away from sin and the damnation it implies. This is obvious when the feature "protection" in angel evokes a guardian spirit.

c) Angels are flying beings, and humans are recognising it in the feature "height" when the word angel comes to mean a certain height.

d) The punishment and the ill-fated end of devils can obviously be found when the lexeme devil yields the idea of "fire". This aspect is present when referring either to a certain kind of food, hot and spicy, or a type of fireworks, an instrument for holding gold to be melted, or an iron grate used for fire.

e) "Bad conditions" are present when devil comes to be used in the area of work activities. In spite of being a rather negative Being in the Christian tradition, the devil has become to be conceptualized as a pitiful and poor Being. Such a conceptualization is far from and totally contrary to Christian doctrine, by which humans must not feel any kind of compassionate feelings towards the devil.

f) The community has certain rich images of how angels and devils are. Both entities have been given a physical appearance and, even, a psychological side. When considered separately, seraphim, cherubim, thrones, dominations, principalities, powers, virtues, archangels, or angels, on one side, and succubus, incubus, demons, or devils, on the other, then each one is given a concrete personality, as if they had been living in the community for centuries. That is, according to the contents of the religious Judeo-Christian doctrine and traditions, the community has subcategorized the prototypes, although the main mappings and projections occur with such prototypes. 
g) The feature "physical or psychic resemblance" is much more productive regarding nonliteral meanings. Thus, it can be seen: (a) In angel, when the term refers to people who look like an angel (in their attributes or acts). (b) In cherub, when it means a surpassing intellect, or a beautiful woman, or an innocent or beautiful child, or a brewer. (c) In seraph, to evoke a person who is innocent, kind or charming, or a kind of fossil-shell. (d) In seraphim, when it is used to refer to Argent in heraldry, a crustacean fossil, a type of moth.

h) The monstrous image of the devil is evident: (a) In demon, when it is used to refer to a person, animal, or action, it epitomizes a malignant nature. (b) In devil, when the term evokes a giant, a type of bird, a kind of tropical shell, or certain mechanical devices. (c) In Satan, when it refers to people or animals as terms of horror or hatred. The similarity regarding psychological parameters is obvious in devil when it designates a devilish human being, a wicked person, an adversary in human form, an unlucky person, a wicked beast, or, when it connotes, from a humorous point of view, qualities applied to Satan.

All these projections have been possible, principally, by means of the cognitive process of imagination. Notwithstanding the only human cognitive process, there are experiences of a different, non-imaginative nature as the basis for imagination to work on. However, such experiences lie on religion as the main source of metaphorical projections. Thus, daily experiences are essential for these projections to take place. The imaginative community has fused their experiences, their knowledge, the imagination and the unknown to enrich its conceptualizations and the way they are expressed in language. The result, we think, apart from enriching, turns out to be fascinating.

\section{CONCLUSIONS}

In the religious lexicon a two-sided focus has been appreciated. On one hand, we can see the experience that the members of a linguistic community live in a direct and personal way; on the other, the virtual creation of such an experience, the "imagined experience". This means that imagination should be attributed the capability of moving and projecting certain notions and ideas to human domains. Such notions and ideas, theologically, can not be placed in such domains.

In studying the religious lexicon of the Beyond, we have noticed how a series of similar projections occur in prototypes (angel, devil) and members of the same category (cherub, seraph; demon, Satan). Thus, certain words share certain aspects, so that such aspects are present in the mappings of domains. As a result of this, it is possible to find a rather similar polysemy in those words that belong to the same category. Some of the 
different meanings that appear in a word can, then, be perceived in a word of the same lexical field (cf. Gibbs and Colston 1995).

Imagination acts as a nexus between the real, earthly World and the Beyond, up to the point that such distant entities become quite familiar and close to our world. As a consequence of such proximity, they become elements in both source and target domains in the production of nonliteral meanings. Since bodily experiences are one of the primary inspirations for metaphorical meanings, the role of imagination is not only relevant, but also essential.

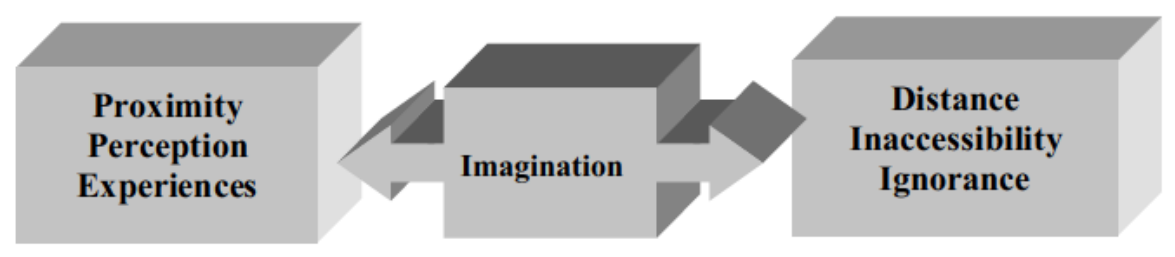

2. Linking role of imagination

\section{REFERENCES}

Cienki, A. 1998. "Straight: An image schema and its metaphorical extensions". Cognitive Linguistics 9, 2: 107-149.

Fernández de la Torre Madueño, M.D. 1997. Significados no literales. Codificación del léxico religioso inglés en el lenguaje coloquial. Servicio de publicaciones de la Universidad de Málaga, Universidad de Málaga.

Fesmire, S. A. 1994. "What is "Cognitive" about Cognitive Linguistics?". Metaphor and Symbolic Activity 9, 2: 149-154.

Geeraerts, D. 1992. "Polysemy and Prototypicality". Cognitive Linguistics 3, 2: 219-231.

Gibbs JR, R.W. And Colston, H.L. 1995. "The cognitive psychological reality of image schemas and their transformations". Cognitive Linguistics 6, 4: 347-378.

Gorayska, B. 1993. "Reflections: A commentary on "Philosophical Implications of Cognitive Semantics"'. Cognitive Linguistics 4, 1: 47-53.

Johnson, M. 1987. The Body in the Mind. The Bodily Basis of Meaning, Imagination and Reason. Chicago: University of Chicago Press.

Johnson, M. 1992. "Philosophical implications of Cognitive Semantics". Cognitive Linguistics 3, 4: 345-366. 
Johnson, M. 1993a. Moral Imagination: Implications of Cognitive Science for Moral Understanding. Chicago: University of Chicago Press.

Johnson, M. 1993b. "Why cognitive semantics matters to philosophy". Cognitive Linguistics 4, 1: 62-74.

Lakoff, G. 1987. Women Fire and Dangerous Things. What Categories Reveal about Mind. Chicago and London: University of Chicago Press.

Lakoff, G. and Johnson, M. 1980. Metaphors We Live By. Chicago: University of Chicago Press.

Lakoff, G. and Turner, M. 1989. More than Cool Reason: A Field Guide to Poetic Metaphor. Chicago: University of Chicago Press.

Leddy, T. 1995. "Metaphor and Metaphysics". Metaphor and Symbolic Activity 10, 3 : 205-222.

Sinha, C. 1993. "Cognitive Semantics and Philosophy: A Reply to Mark Johnson”. Cognitive Linguistics 4, 1: 53-62.

Turner, M. and Fauconnier, G. 1995. "Conceptual integration and formal expression". Metaphor and Symbolic Activity 10, 3: 183-204.

Way, E. C. 1991. Knowledge, Representation and Metaphor. The Netherlands: Kluwer Academic Publishers.

\section{DICTIONARIES}

Mark, P. 1983. Roget's Thesaurus of English Words and Phrases. London: Longman. Oxford English Dictionary on CD-Rom. 1994. Oxford University Press.

Sinclair, J. ed. 1987. Collins Cobuild English Language Dictionary. London and Glasgow: Collins.

Summers, D. 1987. Longman Dictionary of Contemporary English. Essex: Longman. Wilkinson, P.R. 1993. Thesaurus of Traditional English Metaphors. London: Routledge. 